\title{
Rainfall analysis for Indian monsoon region using the merged rain gauge observations and satellite estimates: Evaluation of monsoon rainfall features
}

\author{
S K Roy Bhowmik and Ananda K Das \\ India Meteorological Department, Lodi Road, New Delhi 110 003, India.
}

\begin{abstract}
Objective analysis of daily rainfall at the resolution of $1^{\circ}$ grid for the Indian monsoon region has been carried out merging dense land rainfall observations and INSAT derived precipitation estimates. This daily analysis, being based on high dense rain gauge observations was found to be very realistic and able to reproduce detailed features of Indian summer monsoon. The inter-comparison with the observations suggests that the new analysis could distinctly capture characteristic features of the summer monsoon such as north-south oriented belt of heavy rainfall along the Western Ghats with sharp gradient of rainfall between the west coast heavy rain region and the rain shadow region to the east, pockets of heavy rainfall along the location of monsoon trough/low, over the east central parts of the country, over north-east India, along the foothills of Himalayas and over the north Bay of Bengal. When this product was used to assess the quality of other available standard climate products (CMAP and ECMWF reanalysis) at the grid resolution of $2.5^{\circ}$, it was found that the orographic heavy rainfall along Western Ghats of India was poorly identified by them. However, the GPCC analysis (gauge only) at the resolution of $1^{\circ}$ grid closely discerns the new analysis. This suggests that there is a need for a higher resolution analysis with adequate rain gauge observations to retain important aspects of the summer monsoon over India. The case studies illustrated show that the daily analysis is able to capture large-scale as well as mesoscale features of monsoon precipitation systems. This study with data of two seasons (2001 and 2003) has shown sufficiently promising results for operational application, particularly for the validation of NWP models.
\end{abstract}

\section{Introduction}

There has been a growing operational demand for daily rainfall analysis (gridded data) for a wide range of applications extending from the real time monitoring and prediction of flood events to initialization and validation of Numerical Weather Prediction (NWP) models. Prior knowledge of the structural characteristics of varying rainfall systems is very essential for real time monitoring and prediction of flood events. Despite the increasing demands for high quality rainfall datasets, accurate quantitative documentation of regional rainfall analysis (gridded data) remains as one of the challenging tasks. This is primarily because of the large spatial and temporal variability of rainfall and lack of a comprehensive observing system. The major existing source of large scale rainfall data includes gauge observations, outputs from numerical weather prediction (NWP) models and estimates inferred from satellite observations, and each of these datasets has advantages and disadvantages.

Rain gauge gives relatively accurate point measurement of rainfall but observations are not available over most remote land areas and over oceanic areas. Another problem with the land rain gauge observations is the sampling error if the network

Keywords. Objective analysis; monsoon precipitation system; mesoscale features. 
is not adequately dense. In the case of numerical weather prediction, though there has been rapid progress in recent times, the rainfall prediction skill over tropics is still not up to the satisfactory standard (Roy Bhowmik and Prasad 2001). Satellite observations of infrared (IR) and microwave radiance have been used successfully to retrieve rainfall information over many parts of the globe. But the accuracy of the product is limited due to the indirect relationship of cloud top temperature and precipitation (Richard and Arkin 1981). It is well established (Arkin et al 1989; Janowiak 1992; Ebert and Marshal 1995; Roy Bhowmik and Sen Roy 2006) that satellite precipitation estimates fail to capture orographic rainfall, apart from certain other seasonal and geographical biases. Another limitation of QPE is that it cannot produce more than $72 \mathrm{~mm}$ rainfall in 24 hours, which is not true in the case of monsoon depression or other intense synoptic systems. In spite of these limitations, this is the only source of rainfall observations over the large sea areas. Acknowledgement of the limitations of satellite derived rainfall estimates has led to some recent attempts (Xie and Arkin 1996; Mitra et al 2003) to combine satellite estimates and rain gauge observations so as to take the advantages and strengths of both to produce the best possible analysis. Mitra et al (2003) applied the Cressman technique (Cressman 1959) for objective analysis of rainfall over the Indian monsoon region at the resolution of $1.5^{\circ} \times 1.5^{\circ}$ lat./long. with the use of Indian Geostationary Satellite (INSAT) derived Quantitative Precipitation Estimates (QPE) at $1^{\circ} \times 1^{\circ}$ lat./long. resolution and rain gauge data available from the transmission of the Global Telecommunication System (GTS). In the study (Mitra et al 2003), the number of land stations (about 80 to 140 stations) used for contributing to 185 grid boxes for Indian land region is not adequate. For $150 \mathrm{~km}$ grid spacing, each grid box covers an area of $22,500 \mathrm{~km}^{2}$. Assuming that each rain gauge represents an area of $75 \times 75 \mathrm{~km}^{2}$, it needs at least 4 number of observations for computation of reliable grid box average.

Recently, India Meteorological Department (IMD) has prepared daily gridded rainfall data for the Indian land region using only rain gauge data (Rajeevan et al 2005) following the interpolation method proposed by Shepard (1968). The study (Rajeevan et al 2005) made a quantitative assessment of the high resolution $\left(1^{\circ} \times 1^{\circ}\right.$ lat./long. $)$ daily gridded rainfall data developed for the Indian land region. The study considered daily land station observations for the period from 1951 to 2003 covering the domain from $6.5^{\circ} \mathrm{N}$ to $37.5^{\circ} \mathrm{N}$, $67.5^{\circ} \mathrm{E}$ to $101.5^{\circ} \mathrm{E}$. The study reported that the difference between the IMD and the Global Precipitation Climatology Project (GPCP) data are positive along the west coast, implying that GPCP dataset underestimates the heavy rainfall amounts along the west coast. Similarly over the eastern parts of central India, GPCP data underestimates the heavy rainfall amounts. Over most parts of the country the differences are of the order of $50 \mathrm{~mm}$ for the southwest monsoon season. The correlations between GPCP and IMD rainfall data exceeds 0.4 over central and northwest India. In order to extract the advantage of station observations and to cover the data gap over the sea area, an attempt has been made in the present work to generate daily rainfall analysis at the resolution of $1^{\circ} \times 1^{\circ}$ lat./long. for Indian monsoon region covering the domain from $0^{\circ} \mathrm{N}$ to $40^{\circ} \mathrm{N}, 60^{\circ} \mathrm{E}$ to $100^{\circ} \mathrm{E}$ merging land station observations and satellite estimates (QPE). This is the monsoon domain for which validation of operational NWP models is very important. In this paper, we examine the potential of this merged gridded dataset to capture characteristic features (large scale as well as mesoscale) of the Indian summer monsoon. The analysis for the year 2001 was carried out based on dense rain gauge observations available from synoptic as well as other networks. The analysis for the year 2003 is based on the synoptic observations available on real time basis.

At present, many other monthly standard climate products are available in the literature. These products are derived from the remote sensing observations, in situ measurements from rain gauges and short range forecasts from atmospheric numerical models. It is certainly important to determine the extent to which standard climate products characterize monsoon system. The new objective analysis product is also used to assess the ability of standard climate products to retain important features of the summer monsoon.

The performance of the objective analysis rainfall is also examined on a daily basis for varying synoptic systems with reference to INSAT derived QPE (Arkin et al 1989) and forecast outputs $(24 \mathrm{~h})$ of the operational numerical weather prediction model (Roy Bhowmik and Prasad 2001) of India Meteorological Department (IMD). Synoptic systems are described based on the daily weather bulletin of IMD.

\section{Data sources and methodology}

The objective analysis is carried out for the year 2001 and 2003. There are 576 synoptic stations spread all over the country (India) for which real time rainfall observations are available in operational basis. For the year 2001, to achieve better data coverage, about 1330 daily rain gauge observations received from synoptic as well as 


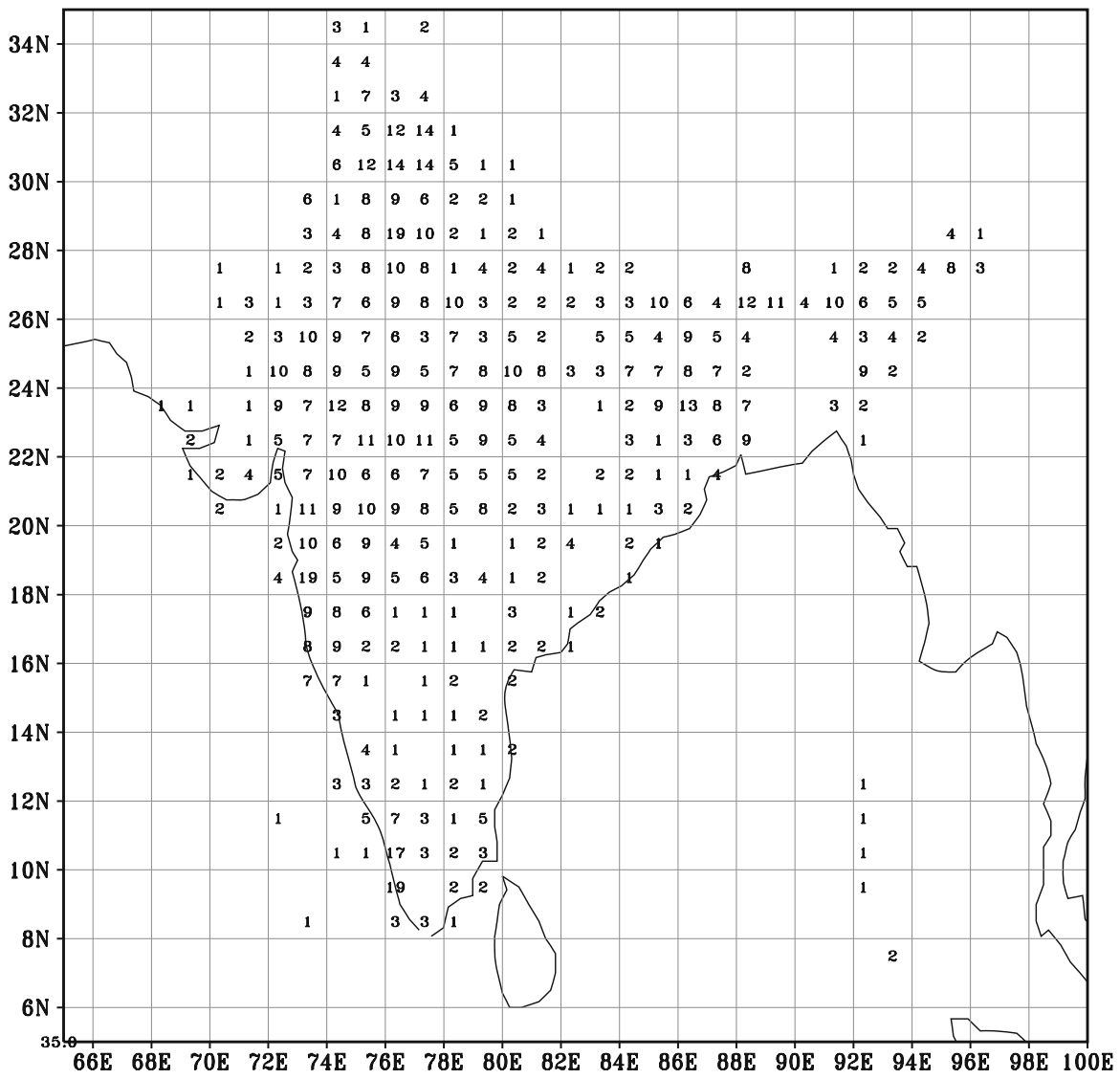

Figure 1. A map of rain gauge numbers per grid square.

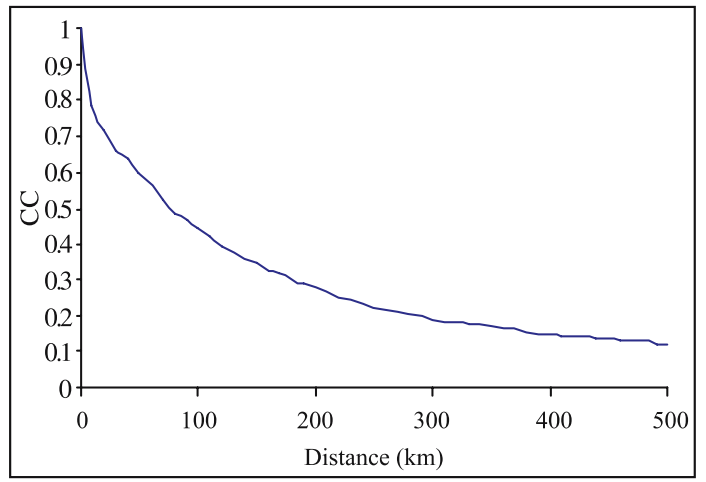

Figure 2. CC curve against distance for the month of August, 2001.

District-wise Rainfall Monitoring Scheme (DRMS) network of IMD are utilized as observed dataset. These stations measure and report rainfall that occurred in the past 24 hours ending at $0830 \mathrm{~h}$ of Indian Standard Time (0300 UTC). Before archiving the data, IMD makes multistage quality control of observed values. Standard quality control is performed before carrying out the objective analysis. First, station information (especially location) is verified. The precipitation values themselves are checked for coding or typing errors. The density of the spatial data used to generate the objective analysis product is presented in figure 1 . The figure depicts the gauge number per $1^{\circ} \times 1^{\circ}$ lat./long. grid square. The observations from neighbouring countries like Pakistan, Bangladesh, Myanmar and from the Himalayan areas are absent.

For the current objective analysis methods being used for rainfall analysis, the initial assessment of the radius of rainfall influence is one of the most important parameter. All the weighting functions that are proposed by various researchers (Cressman 1959; Thiebaux and Pedder 1987, etc.) for the objective analysis of rainfall appear as functions of the distance between grid point and the sites only. In a very recent study, Roy Bhowmik et al (2005) applied the technique of correlation co-efficient (CC) as the function of distance for objective determination of radius of influence of rainfall over the Indian monsoon region. The correlation co-efficient $(\mathrm{CC})$ of rainfall between rain gauges in discrete distance intervals is computed, and the distance at which CC falls to 0.3 is chosen as the radius of rainfall influence. The method is tested for different synoptic situations as well as for the different sectors of the country to find the geographical variation of radius of influence. The study showed that the radius of influence 
of rainfall over the Indian region, in general, is around $200 \mathrm{~km}$. For example, figure 2 illustrates the CC curve against distance when the method is applied for the monthly mean rainfall observations of August 2001.

In any objective analysis technique, the main idea is that the estimation at any point is considered as a weighted average of the mean values of irregular sites. If $Z_{i, m}$ are the observations from $i=1,2, \ldots, n$ measurement sites, then following Sen (1997), the estimated value $Z_{m}$ at the grid point $m$ can be written as:

$$
Z_{m}=\left[\frac{\sum_{i=1}^{n} W\left(r_{i, m}\right)}{\sum_{i=1}^{n} W\left(r_{i, m}\right)}\right],
$$

where the weighting function $W\left(r_{i, m}\right)$ is defined as (Thiebaux and Pedder 1987):

$$
\begin{array}{rlrl}
W\left(r_{i, m}\right) & =\left(\frac{R^{2}-r_{i, m}^{2}}{R^{2}+r_{i, m}^{2}}\right)^{2}, & & \text { for } \quad r_{i, m}<R \\
& =0, & \text { for } \quad r_{i, m} \geq R,
\end{array}
$$

$R$ is called the radius of influence and $r_{i, m}$ is the distance between $i$ th site and the estimation point $m$. For the present study $R$ is considered as $200 \mathrm{~km}$ (Roy Bhowmik et al 2005). In the above equation, the distance function is used to convert station observations into regular grids of $1^{\circ} \times 1^{\circ}$ lat./long.

In order to extract the advantage of rain gauge data over land areas and satellite estimates over oceans, the gridded rain gauge data over land areas are merged with the QPE over oceans and over the rain gauge gap areas. Calculation of estimated rainfall $Z_{m}$ at the grid point $m$ makes use of all the observations and the distances from the grid point which falls within the radius of $200 \mathrm{~km}$. For the case when no site within the distance $R(200 \mathrm{~km})$ is available (for the data gap), QPE values are considered for that grid point. The datasets for this study cover the area between lat. $0^{\circ}$ to $40^{\circ} \mathrm{N}$ and long. $60^{\circ}$ to $100^{\circ} \mathrm{E}$. The monthly mean rainfall obtained averaging the regular grids is then compared with the rainfall estimates from other sources.

The study is based on daily rainfall data for the period from 1 June to 30 August of summer monsoon 2001. For the year 2003, daily rainfall observations (for the same data period) received on the real-time (around 250 stations) from the transmission of Global Telecommunication System (GTS) are utilized for the daily analysis. In the year 2001, QPE data was available from INSAT1D. The satellite was defunct in 2002. For the year 2003, QPE available from the INSAT-Kalpana-1 has been used for the analysis.

\section{Salient features of Indian summer monsoon during 2001 and 2003}

In the monsoon season of 2001, total rainfall for the whole of the country was $91 \%$ of the long term average normal. Onset of monsoon over Kerala (extreme southern state) was on 21 May, about one week earlier than the normal date of 1 June. The monsoon covered the entire country on 3 July, 12 days earlier than the normal date of 15 July. One depression formed in June. Monsoon trough was established on 3 July and Tibetan anticyclone on 12 June. The cross equatorial flow was, in general, active during June to August over the Arabian Sea and Bay of Bengal.

In the monsoon season of 2003, total rainfall was $102 \%$ of long term normal. This is in spite of onset over Kerala being on 8 June, late by a week of its normal date of 1 June. The monsoon covered the entire country on 5 July, 10 days prior to the normal date of 15 July. Two depressions formed during this season both over the Bay of Bengal. The first one experienced during 25-28 July and second one during 27-28 August. Monsoon trough got established on 5 July. Cross equatorial flow was quite normal in general during the entire season over the Arabian Sea and Bay of Bengal during most of the days.

\section{Quantitative inter-comparison between the new analysis and the QPE}

In order to quantify the difference between the new analysis and INSAT-derived QPE over land areas of the Indian region, spatial distributions of mean error (QPE-analysis), root mean square error (RMSE) and correlation coefficient (CC) between QPE and analysis (1 June to 30 August, 2001) are illustrated in figure $3(\mathrm{a}, \mathrm{b}, \mathrm{c})$. The QPE shows considerable underestimation of orographic rainfall (10 to $20 \mathrm{~mm}$ ) along the west coast of India and along the foothills of Himalayas. Whereas it shows excessive (within $5 \mathrm{~mm}$ ) rainfall over east central parts of the country, over the domain of south-eastern end of monsoon trough. No appreciable difference is noticed between QPE and the analysis field over the rest of the country. The RMSE ranges between 20 and $30 \mathrm{~mm}$ along the west coast (Western Ghat), eastern part of monsoon trough and over few pockets along the foothills of the Himalayas. The RMSE decreases over the remaining parts of the country and remains within a reasonably small range. The $\mathrm{CC}$ over most part of the country has been around 0.6 . The inter-comparison clearly indicates that the new analysis could take advantage of rain gauge observations over land areas where performance 

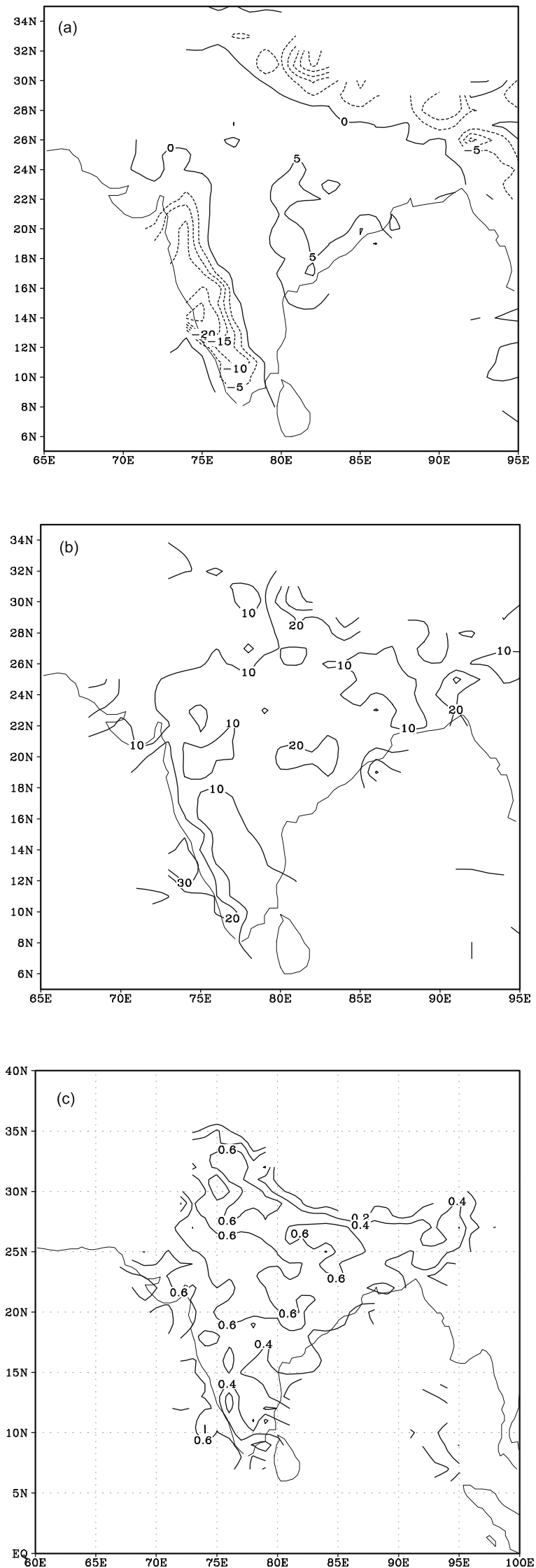

Figure 3. Spatial distribution of (a) mean error ( $\mathrm{mm}$ ) (QPE-analysis), (b) root mean square errors ( $\mathrm{mm})$ and (c) CC between analysis and QPE for the data period 1 June to 30 August, 2001 of satellite estimates is poor, particularly for orographic rainfall.

\section{Evaluation of monthly features}

The plots of monthly mean rain gauge observations for the month of June, July and August 2001 are shown in figure $4(\mathrm{a}-\mathrm{c})$. In order to avoid overlapping of figures between two neighbouring stations, rainfall figures are plotted in $\mathrm{cm}$ and rainfall less than $10 \mathrm{~mm}$ is not considered for plotting. The corresponding objective analysis is illustrated in figure $4(\mathrm{~d}-\mathrm{f})$.

We begin with a description of monthly mean rainfall (rain gauge observations) for the month of June. The rainfall plot shows that along the west coast and over the extreme northeastern parts of the country mean rainfall exceeded $30 \mathrm{~mm}$. Over central parts of the country and over remaining northern parts of the country 10 to $20 \mathrm{~mm}$ rainfall was received by most stations. The corresponding objective analysis shows a north-south oriented belt of heavy rainfall along the Western Ghats with a peak centered near lat. $11^{\circ} \mathrm{N}(35 \mathrm{~mm})$. The sharp gradient of rainfall between the west coast heavy rain region and the rain shadow region to the east is brought out realistically in the objective analysis. The pockets of heavy rainfall (15 to $30 \mathrm{~mm}$ ) over east central parts of India, north-east India, foothills of Himalayas and over north Bay of Bengal are well captured in the objective analysis. The analysis is found to be consistent with the observations.

During the month of July, rainfall activity over the country increases. The monthly mean rainfall map shows that most parts of the country, except southern peninsula received rainfall in the order of 20 to $40 \mathrm{~mm}$. Rainfall along west coast and extreme northeastern and northwestern parts of the country exceeded $30 \mathrm{~mm}$. The mean rainfall map is found to be well matched with the objective analysis. The objective analysis produces realistically high values (more than $30 \mathrm{~mm}$ ) of rainfall along the west coast as reported in the mean rainfall map. The sharp gradient of rainfall between the west coast heavy rain region and the rain shadow region to the east persisted. The rainfall (10 to $30 \mathrm{~mm}$ ) along the monsoon trough region (east central India) extending from northwest to southeast direction up to north Bay of Bengal is also found to be realistic, another pocket of higher rainfall of amount more than $40 \mathrm{~mm}$ is noticed along the foothills of the Himalayas.

In the month of August, in the mean rainfall map, observed heavy rainfall is found to be located along the west coast, over east central parts and northern parts of the country where rainfall 

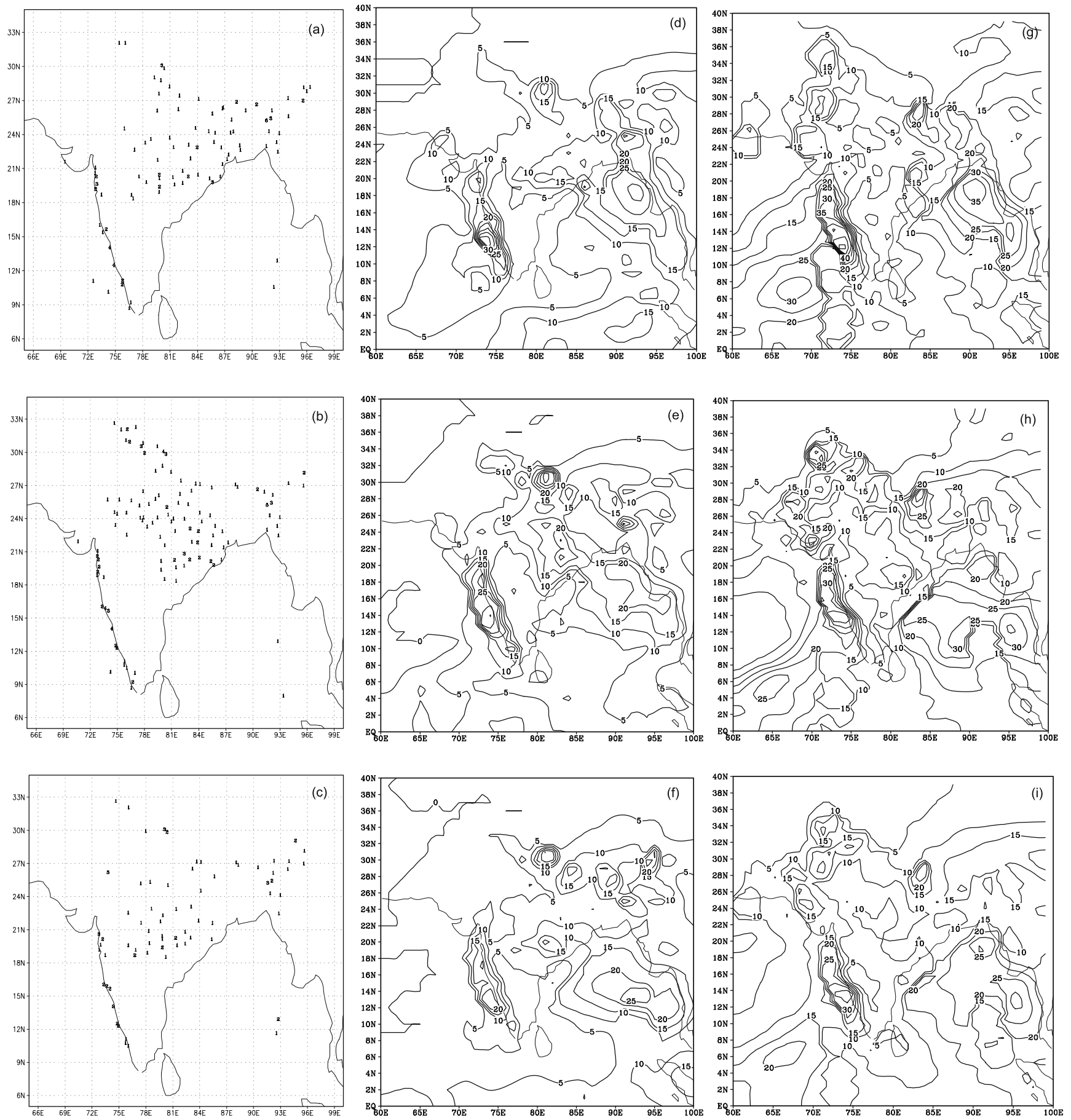

Figure 4. $\quad(\mathbf{a}-\mathbf{c})$ Plots of mean land rain gauge observations $(\mathrm{cm}),(\mathbf{d}-\mathbf{f})$ Spatial distribution of corresponding mean rainfall $(\mathrm{mm})$ based on objective analysis combining rain gauge observations and INSAT QPE for the month of June, July and August 2001; (g-i) Spatial distribution of mean rainfall $(\mathrm{mm})$ based on objective analysis combining rain gauge observations and satellite Kalpana-1 QPE for June, July and August of 2003.

ranges between 10 and $20 \mathrm{~mm}$. The corresponding objective analysis continues to produce heavy rainfall belts along the Western Ghats (peak $20 \mathrm{~mm}$ ), along the foothills of Himalayas, over east central India and adjoining Bay of Bengal (peak 15 to $25 \mathrm{~mm})$.

The inter-comparison clearly reveals that the plotted station rainfall is consistent with the corresponding objective analysis of rainfall. The objective analysis product, being based on significantly high dense rain gauge observations, was found to be very realistic as expected. The important characteristics of Indian summer monsoon like, north-south oriented belt of heavy rainfall along the Western Ghats with sharp gradient of rainfall between the west coast heavy rain region 
and the rain shadow region to the east, pockets of heavy rainfall along the location of monsoon trough/low over east central parts of country, over north-east India, along the foothills of Himalayas and over north Bay of Bengal are brought out realistically in the objective analysis.

For the year 2003, figure 4(g, h, i) illustrates the spatial distribution of monthly mean rainfall for the month of June, July and August based on the objective analysis. In the month of June, the mean rainfall distribution shows a north-south oriented belt of heavy rainfall along the west coast between latitude $6^{\circ} \mathrm{N}$ and $20^{\circ} \mathrm{N}$ with a peak centered near lat. $10^{\circ} \mathrm{N}(45 \mathrm{~mm})$. The eastwest gradient of rainfall between west coast heavy rainfall and rain shadow area is found to be very strong. Another heavy rainfall belt is located (20 to $35 \mathrm{~mm}$ ) over north Bay of Bengal where the monsoon low originates, with center near lat. $18^{\circ} \mathrm{N} /$ long. $90^{\circ} \mathrm{E}$. The third heavy rainfall belt is noticed along the foothills of Himalayas (20 to $25 \mathrm{~mm}$ ) and over northwest India. Another heavy rainfall zone with a peak of $30 \mathrm{~mm}$ is located over southeast Arabian Sea, where the amount of rainfall decreases gradually to the north. In the month of July, the observed rainfall distribution continues to describe the orographic heavy rainfall belt along the west coast between latitude $8^{\circ} \mathrm{N}$ and $20^{\circ} \mathrm{N}$ with a peak centered near lat. $13^{\circ} \mathrm{N}(35 \mathrm{~mm})$. A few heavy rainfall belts ( 15 to $20 \mathrm{~mm}$ ) are noticed along the foothills of Himalayas, northwest India and over large areas in the central Bay of Bengal and south Arabian Sea. Along the domain of monsoon trough 10 to $15 \mathrm{~mm}$ rainfall is noticed. In the month of August, the objective analysis continues to show heavy rainfall belts along the Western Ghats (peak $20 \mathrm{~mm}$ ) and over northwest India (peak $20 \mathrm{~mm}$ ) and over east central India (peak $10 \mathrm{~cm}$ ).

The spatial pattern based on daily objective analysis is found to be consistent with the monthly rainfall maps documented by the India Meteorological Department (2003) based on land rain gauge observations. According to the report of India Meteorological Department (2003), in the month of June, along west coast and over extreme northeastern parts of the country mean rainfall exceeded $20 \mathrm{~mm}$. Over the northeastern parts of the country more than $15 \mathrm{~cm}$ rainfall was received. During the month of July, most parts of the country received rainfall of the order of $15 \mathrm{~mm}$. Rainfall along the west coast and over extreme northeastern parts of the country was more than $35 \mathrm{~mm}$. In the month of August, observed heavy rainfall peaks are located along the west coast, over east central parts and over extreme northeastern parts of the country where rainfall exceeds $15 \mathrm{~mm}$. It is interesting to note that the objective analysis from the use of real time synoptic observation is also capable of reproducing characteristic features of summer monsoon.

\section{Inter-comparison with other standard climate products}

Availability of this new objective analysis product provides us with an opportunity to compare with and to determine the extent to which other standard climate products bring out characteristic features of monsoon rainfall. The standard climate products considered for this study are: Climate Prediction Center (CPC) Merged Analysis of Precipitation (CMAP) (Janowiak and Xie 1999) and the reanalysis of the European Center for Medium Range Weather Forecasting (ECMWF), both are available at the resolution of $2.5^{\circ}$ grid. We also consider the rainfall analysis prepared under the Global Precipitation Climatology Centre (GPCC) at the resolution of $1^{\circ}$ grid (Rudolf et al 1994; Adler et al 2003) based on land rain gauge observations only (http://www.dwd.de/pub/data/gpcc/ download.html).

The monthly rainfall distributions based on the ECMWF reanalysis for the month of June, July and August of 2001 are shown in figure $5(\mathrm{a}-\mathrm{c})$. In June, the amount of orographic rainfall along the Western Ghats is significantly less. Rainfall pockets of the order of 15 to $25 \mathrm{~mm}$ are noticed over the head Bay of Bengal and along the foothills of Himalayas. The reanalysis continues to fail to capture orographic rainfall along Western Ghats in July. It could capture a rainfall amount of the order of 15 to $20 \mathrm{~mm}$ over the head Bay of Bengal and along the foothills of Himalayas. In August, the reanalysis exhibits rainfall pockets of magnitude 15 to $20 \mathrm{~mm}$ along the foothills of Himalayas and $15 \mathrm{~mm}$ over central Bay of Bengal. The product, being based on short range NWP forecast at the resolution of $2.5^{\circ}$ grid, could not capture orographic rainfall along the west coast. It also fails to capture rainfall belt over east central parts of the country along the active rainfall zone of monsoon trough.

The monthly rainfall products for the month of June, July and August of 2001 based on GPCC are presented in figure $5(\mathrm{~d}-\mathrm{f})$. In June, the rainfall pattern shows a north-south oriented belt of heavy rainfall along the Western Ghats with a peak centered near lat. $10^{\circ} \mathrm{N}(20-25 \mathrm{~mm})$. The gradient of rainfall between the west coast heavy rain region and the rain shadow region to the east is clearly brought out in the analysis. Another heavy rainfall belt is (15 to $35 \mathrm{~mm}$ ) located over northeast India and adjoining Bangladesh and Myanmar. But pockets of heavy rainfalls over east central parts of the country and along the foothills of 

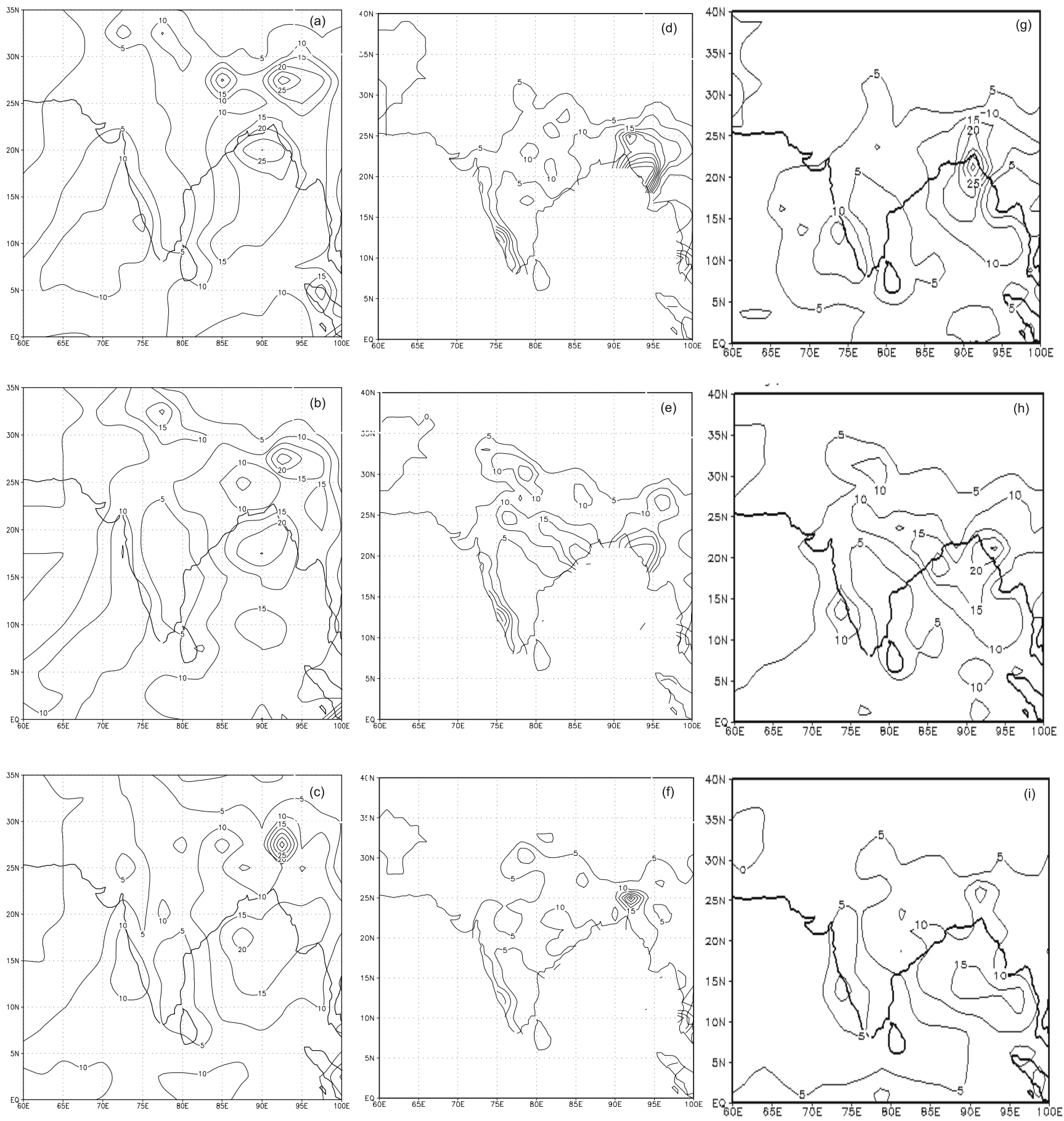

Figure 5. Spatial distribution of mean rainfall $(\mathrm{mm})$ based on $(\mathbf{a}-\mathbf{c})$ ECMWF analysis, $(\mathbf{d}-\mathbf{f})$ GPCC analysis, $(\mathbf{g}-\mathbf{i})$ CMAP analysis for the month of June, July and August 2001.

Himalayas are found to be underestimated. In July, the GPCC analysis continued to produce closely realistic amounts of rainfall (20 to $30 \mathrm{~mm}$ ) along the west coast. The gradient of rainfall between the west coast heavy rain region and the rain shadow region to the east persisted. The rainfall (10 to $20 \mathrm{~mm}$ ) along the monsoon trough region (east central India) is also seen to be realistic. But the heavy rainfall belt along the foothills of Himalayas continues to be underestimated. In the month of August, the rainfall amount is slightly reduced, but it could clearly capture rainfall belts along the Western Ghats (peak $15 \mathrm{~mm}$ ) and over east central India. A small pocket of heavy rainfall of the order of $15-$ $30 \mathrm{~mm}$ is located centered over northeast India and its neighbourhood. 
Figure 5(g-h) presents CMAP products for the month of June, July and August of 2001. In June, CMAP shows rainfall of the order of 10 to $15 \mathrm{~mm}$ along Western Ghats, $30 \mathrm{~mm}$ over the head Bay of Bengal and adjoining land areas, over the domain of monsoon depression. The orographic rainfall along the Western Ghats is significantly underestimated. Rainfall pockets along the foothills of Himalayas are found to be missing. In July, the merged analysis could produce rainfall of the order of 10 to $15 \mathrm{~mm}$ along Western Ghats confined between lat. $8^{\circ} \mathrm{N}$ to $12^{\circ} \mathrm{N}$ and over the domain of monsoon trough and 15 to $20 \mathrm{~mm}$ over north Bay of Bengal. In August, the merge analysis captured rainfall of the order of 5 to $10 \mathrm{~mm}$ along the Western Ghats and 10 to $15 \mathrm{~mm}$ over north and central Bay of Bengal. Comparison reveals that due to coarser resolution and inadequacy of gauge observations, the CMAP fails to resolve important monsoon features. However, no significant difference is noticed over sea areas where both the datasets are based on satellite estimates.

The inter-comparison clearly reveals that the GPCC rainfall distribution at the resolution of $1^{\circ}$ grid closely discerns the new objective analysis. It could capture the orographic as well the gradient of rainfall along the west coast. This suggests that there is a need for higher resolution analysis with adequate rain gauge observations to retain important aspects of the summer monsoon over India.

\section{Evaluation of structural characteristics of monsoon rainfall system}

Monsoon low pressure system is the main rainproducing system of summer monsoon over the Indian region which forms over northwest Bay of Bengal and moves northwestwards across the country giving rise to heavy-to-very heavy falls during its passage. Along the west coast of India heavy rainfall occasionally occurs in association with offshore trough. In some occasions, the offshore trough becomes so well-marked that offshore vortex could also be located. Mid-tropospheric circulation is an important monsoon rain-producing system which occasionally causes heavy rainfall over the west central parts of the country. In this section, structural characteristics of these monsoon rainfall systems are investigated from the use of this new objective analysis.

\subsection{Monsoon low pressure system}

On 17 July, a low pressure area lay over east central parts of the country with associated cyclonic circulation extending up to mid-tropospheric levels, tilting southwestwards with height. The associated spatial distribution of rainfall based on objective analysis, QPE and NWP model of IMD is shown in figure $6(\mathrm{a}-\mathrm{c})$ respectively. The rainfall analysis shows a heavy rainfall zone centered near lat. $21^{\circ} \mathrm{N} /$ long. $84^{\circ} \mathrm{E}$ with a peak magnitude of the order of $140 \mathrm{~mm}$ which extends southwestwards. Whereas satellite rainfall estimates could capture rainfall of the order of 40 to $60 \mathrm{~mm}$ over the area. The NWP model of IMD shows rainfall of the order of $40 \mathrm{~mm}$ to the east of the observed location.

\subsection{Off-shore trough}

On 5 July, an offshore trough on sea level chart ran off west coast of India. The corresponding rainfall distribution based on objective analysis, satellite and NWP model is presented in figure $6(\mathrm{~d}-\mathrm{f})$ respectively. The objective analysis could produce north-south oriented rainfall belt along the coast with a few pockets of maxima ranging from $40 \mathrm{~mm}$ to $60 \mathrm{~mm}$ rainfall, indicating the presence of offshore vortex along the trough. This rainfall activity is found missing in the QPE. The NWP model of IMD could capture a rainfall amount of $20 \mathrm{~mm}$ over the coastal belt. On 8 July, the offshore trough is located over the same area. The corresponding rainfall pattern based on objective analysis is shown in figure $6(\mathrm{~g})$. In the analysis three pockets of heavy rainfall along the west coast are noticed. The rainfall maxima of the order of $140 \mathrm{~mm}$ rainfall over the area with centre near lat. $17.5^{\circ} \mathrm{N} /$ long. $75^{\circ} \mathrm{E}$ suggests the presence of an off shore vortex. No rainfall activity is noticed both in the QPE as well as in the NWP model outputs (figure not shown).

\subsection{Mid-tropospheric circulation}

On 3 July 2001, a cyclonic circulation extending up to mid-tropospheric level lay over west central India tilting southwestwards with height. Associated rainfall as revealed in the objective analysis, QPE and model are shown in figure $6(\mathrm{~h}-\mathrm{j})$ respectively. In the objective analysis, heavy rainfall belt extending over a large domain towards northwest and south and east with a peak of $12 \mathrm{~cm}$ rainfall centred near lat. $25^{\circ} \mathrm{N}$ long. $75^{\circ} \mathrm{E}$ is observed. Corresponding satellite estimates also show a heavy rainfall zone covering a larger area with a peak intensity of $60 \mathrm{~mm}$ rainfall centered near lat. $24.2^{\circ} \mathrm{N} /$ long. $73^{\circ} \mathrm{E}$. The NWP model could produce $20 \mathrm{~mm}$ rainfall over the area.

The case studies illustrated above reveal that the synoptic as well as mesoscale characteristics of monsoon precipitation systems are realistically reproduced by the new objective analysis. 

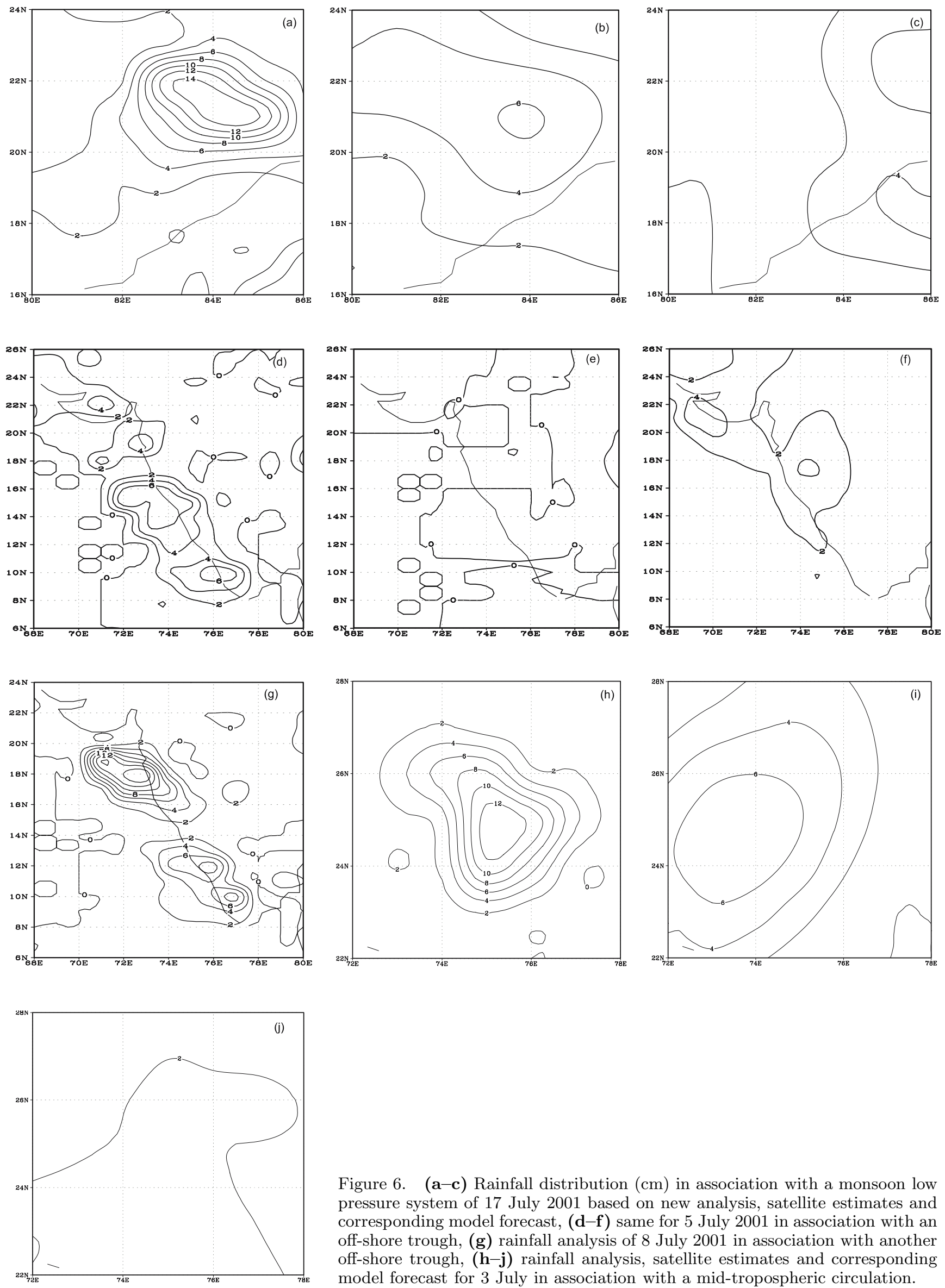

Figure 6. (a-c) Rainfall distribution $(\mathrm{cm})$ in association with a monsoon low pressure system of 17 July 2001 based on new analysis, satellite estimates and corresponding model forecast, $(\mathbf{d}-\mathbf{f})$ same for 5 July 2001 in association with an off-shore trough, (g) rainfall analysis of 8 July 2001 in association with another off-shore trough, $(\mathbf{h}-\mathbf{j})$ rainfall analysis, satellite estimates and corresponding model forecast for 3 July in association with a mid-tropospheric circulation. 


\section{Summary and concluding remarks}

In this paper, an attempt has been made to generate daily rainfall analysis at the resolution of $1^{\circ} \times 1^{\circ}$ lat./long. for the domain from $0^{\circ} \mathrm{N}$ to $40^{\circ} \mathrm{N}, 60^{\circ} \mathrm{E}$ to $100^{\circ} \mathrm{E}$ over the Indian monsoon region merging dense rain gauge observations over land and satellite estimates over data gap areas.

The study demonstrates the potential of this merged dataset for the monitoring and analysis of monsoon precipitation systems. The quantitative inter-comparison with the INSAT QPE shows that the new analysis could take the advantage of rain gauge observations over land areas where the performance of the satellite estimates is poor, particularly for orographic rainfall. The result shows that daily rainfall analysis with use of dense rain gauge observations (for the year 2001) could capture all realistic features of Indian summer monsoon. When the analysis is carried out with use of real time synoptic observations for the year 2003, the new analysis could retain the characteristic features of monsoon rainfall.

This product is used to evaluate the quality of other available standard climate products CMAP and ECMWF reanalysis at the resolution of $2.5^{\circ}$ grid. It is found that the orographic heavy rainfall along Western Ghats of India is poorly represented by both of them. CMAP also fails to capture orographic rainfall along the foothills of Himalayas and ECMWF fails to reproduce rainfall belt over east central India, over the domain of monsoon trough. No significant difference is noticed over sea areas. On the other hand, GPCC analysis (gauge only) at the resolution of $1^{\circ}$ grid closely discerns the new analysis. The inter-comparison highlighted the limitations of the coarser resolution standard climate products, which are derived from the remote sensing observations, short range forecasts from atmospheric numerical models and meager in situ rain-gauge observations to address detailed aspects of Indian summer monsoon. This suggests that there is a need for higher resolution analysis with adequate rain gauge observations to retain important aspects of the summer monsoon over India.

The case studies illustrated show that the daily rainfall analysis is able to capture large scale as well as mesoscale features of monsoon precipitation systems. This study with data of two seasons shows sufficiently promising results for operational applications. Availability of this improved analysis is expected to benefit various user communities involved with the task of monitoring and prediction of monsoon activity and flood events.

\section{Acknowledgement}

The authors are thankful to the Director General of Meteorology, India Meteorological Department for providing all facilities to carry out this work and for permissions to publish the paper.

\section{References}

Adler R F, Huffman G J and Co-authors 2003 The version 2 Global Precipitation Climatology Project (GPCP) Monthly precipitation analysis (1979-present); J. Hydrometeorology 4 1147-1167.

Arkin P A, Rao A V R K and Kelkar R R 1989 Largescale precipitation and out-going long-wave radiation from INSAT- 1B during 1986 southwest Monsoon season; J. Climate 2 619-628.

Cressman G P 1959 An operational objective analysis system; Mon. Wea. Rev. 87 367-374.

Ebert E and Marshall J L 1995 An evaluation of infrared satellite estimates techniques over Australia; Aust. Meteor. Mag. 44 177-190.

India Meteorological Department 2003 Climate Diagnostic Bulletin of India - June, July, August 2003; Rep. No. 88, 89 and 90, National Climate Centre, IMD, Pune.

Janowiak J E 1992 Tropical rainfall: A comparison of satellite derived rainfall estimates with model precipitation forecast, climatologies and observations; Mon. Wea. Rev. $120448-462$.

Janowiak J E and Xie P 1999 CMAPS-OPI: A global satellite rain gauge merge product for real time precipitation monitoring application; J. Climate 12 $3335-3342$.

Mitra A K, Das Gupta M, Singh S V and Krishnamurti T N 2003 Daily rainfall for the Indian Monsoon region from merged satellite and rain gauge values: Large scale analysis from the real-time data, J. Hydrometeorology 4 769-781.

Rajeevan M, Bhate J, Kale J D and Lal B 2005 Development of a high resolution daily gridded rainfall data for Indian region; Met. Monograph Climatology No. 22/2005, India Meteorological Department, Pune, pp 26 .

Richard F and Arkin P 1981 On the relationship between satellite observed cloud cover and precipitation; Mon Wea. Rev. 109 1081-1093.

Roy Bhowmik S K and Prasad K 2001 Some characteristics of Limited Area Model Precipitation Forecast of Indian Monsoon and evaluation of associated flow features; Meteor. Atmos. Phys. 76 223-236.

Roy Bhowmik S K, Joardar D and Das Ananda K 2005 Radius of rainfall influence over Indian monsoon region; Geofizika 22 131-141.

Roy Bhowmik S K and Sen Roy Soma 2006 Principal Component Analysis to study spatial variability of errors in the INSAT derived quantitative precipitation estimates over Indian monsoon region; Atmosfera $\mathbf{1 9}$ 255-265.

Rudolf B, Hauschild H, Rueth W and Sucheider U 1994 Terrestrial precipitation analysis: operational method, required density of point measurements; Global precipitation and Climate change (eds) Desbais $\mathrm{M}$ and Desahmond F, Springer Verlag, 173-186. 
Sen Zekia 1997 Objective Analysis by Cumulative Semivariogram technique and its application in Turkey; J. Appl. Meteor. 36 1712-1724.

Shepard D 1968 A two dimensional interpolation function for irregularly spaced data; Proc. 1968 ACM Nat. Conf, pp 517-524.
Thiebaux H J and Pedder M A 1987 Spatial Objective analysis: with Applications in Atmospheric Science (London: Academic Press) 299 pp.

Xie P and Arkin P A 1996 Analysis of global monthly precipitation using gauge observation, satellite estimates and numerical model precipitation; J. Climate 9 840-858.

MS received 16 February 2006; revised 18 September 2006; accepted 5 February 2007 